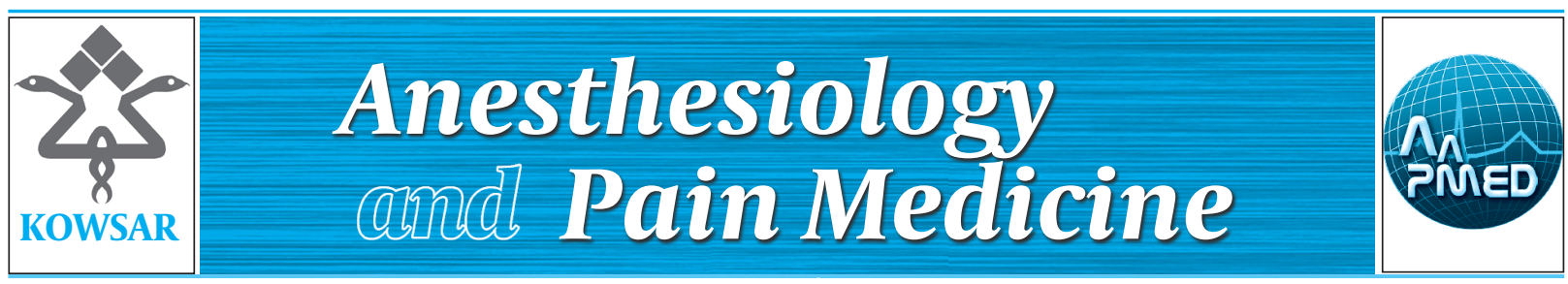

\title{
Evolution and Mode of Action of Pulsed Radiofrequency
}

\author{
Menno E. Sluijter ${ }^{1,{ }^{*},}$, Farnad Imani ${ }^{2}$ \\ ${ }^{1}$ Department of Pain Medicine, Swiss Paraplegic Center, Nottwil, Switzerland \\ ${ }^{2}$ Department of Anesthesiology and Pain Medicine, Rasoul Akram Medical Center, Tehran University of Medical Sciences, Tehran, IR Iran \\ * Corresponding author: Menno E. Sluijter, Sluijter, Department of Pain Medicine, Swiss Paraplegic Center, Nottwil, Switzerland. Tel.: +41-419394920, E-mail: \\ msluijter@mac.com.
}

Keywords: Pulsed Radiofrequency Treatment; Ablation Techniques; Anti-Inflammatory Agents; Immune System

The rationale of Pulsed Radiofrequency (PRF) was clear and simple. The mode of action of conitnuous Radiofrequency (CRF) could be explained by destruction of afferent nerve fibers on their way from a nociceptive focus to the central nervous system. In the late eighties there was a new discussion on the validity of this theory. It had been observed that an RF lesion could also be effective if it was applied peripheral to the nociceptive focus. This was in conflict with the widely accepted concept. It was therefore suspected that a second mechanism might be operational during RF application. PRF was invented to explore this possibility, with the sole purpose of finding a less destructive and equally effective technique for the application of RF to afferent pathways. This has not come true. PRF has not developed into a technique that is suitable to block afferent signals in nerves close to the electrode. It has however developed in a direction that could not have been foreseen by the inventors at that time. PRF developed into a new direction when in 2005 Teixeira found that intraarticular application of PRF could relieve pain. This was published eventually in 2008 (1) and it is confirmed by the results in larger series of patients in this issue (2). The importance of this finding goes far beyond finding another useful indication for PRF. It implies that contrary to the effects of CRF the action of PRF is not implicitly limited to an action on nerves. The immune system came into focus, suggesting that PRF could possibly influence the nociceptive process itself. An initial report on a second invention by Teixeira is published in this issue (3). Its background follows from his invention of intra-articular PRF. If PRF has a local anti-inflammatory effect it might possibly also have a general effect on the immune system if the mode of application could be adapted. The scope of this new method may have large dimensions because the immune system is involved in so many pathological conditions. This goes beyond well-known conditions like the autoimmune diseases. For example, stress and allostatic load are connected to a whole list of serious diseases such as cancer and cardiovascular disease $(4,5)$. The mode of action of PRF has still not been elucidated. The first attempts to find an explanation (6) were in line with the CRF concept, which was quite natural at the time. PRF was applied on a healthy

Article type: Editorial; Received: 04 Jan 2013, Accepted: 14 Jan 2013; DOI: 10.5812/aapm.10213

-Implication for health policy/practice/research/medical education:

PRF was initially regarded as a method of blocking nociceptive stimuli that is less destructive than a thermolesion. Since the introduction of the intra-articular application this concept has changed. PRF is now thought to have an anti-inflammatory effect on the immune system, acting on the nociceptive process itself instead of on the afferent innervation.

$\checkmark$ Please cite this paper as:

Sluijter ME, Imani F. Evolution and Mode of Action of Pulsed Radiofrequency. Anesth Pain. 2013;2(4):139-141. DOI: 10.5812/aapm.10213

Copyright ( 2013, Iranian Society of Regional Anesthesia and Pain Medicine (ISRAPM); Published by Kowsar Corp.

This is an Open Access article distributed under the terms of the Creative Commons Attribution License (http://creativecommons.org/licenses/by/3.0), which permits unrestricted use, distribution, and reproduction in any medium, provided the original work is properly cited. 
nerve in the absence of a painful condition. It was found that the application of PRF to a DRG elicits the expression of c-fos in the dorsal horn. The importance of this finding for the clinical effect of PRF is still a subject of discussion. C-fos is an aspecific marker indicating cellular activity. The suggestion that Long Term Depression (LTD) of higher afferent synapses could have developed was hypothetical. The meaning of the dorsal horn activity was never cleared up and the discussion therefore ended undecided. The alternative of modulation is clearly ablation, and in the vacuum that had persisted this possibility came up (7). Tissue destruction does occur during PRF (8-10). Theoretically this could be due either to overheating or to exposure to electric fields. The thermal effects are limited because the temperature falls off rapidly away from the electrode tip and because the shaft does not heat up at all $(11,12)$. A more likely candidate for causing destruction is exposure to electric fields. From Cabana's work (13) it can be deducted that for a PRF duty cycle cell death occurs at field strength from about $10.000 \mathrm{~V} / \mathrm{m}$ upwards. The maximal fields around the tip are particularly high, approximately $180.000 \mathrm{~V} / \mathrm{m}$ when the customary $45 \mathrm{~V}$ is applied (11) and this is far into the lethal range. But just like the temperature the field strength falls off precipitously away from the electrode. The electric fields around the shaft start less spectacularly at around $50.000 \mathrm{~V} / \mathrm{m}$ but they are much more persistent away from the electrode. These fields are a likely candidate for causing the reported destruction. But this narrow zone of destruction around the shaft cannot explain the mode of action of PRF. That could only be suspected if the electrode is parallel and closely adjacent to the target structure. This does not apply, for example in DRG procedures and in intra-articular procedures. A minimal ablative effect may therefore occur in special electrode positions, but explaining the mode of action of PRF in general terms by ablation is a bridge too far. An explanation of the mode of action should preferably be universal. The role of transcutaneous PRF then becomes particularly important. The efficacy of this method has now been shown in an RCT (14) and the elicited fields can be estimated to be approximately $500 \mathrm{~V} / \mathrm{m}$. Do such low fields have a biological action? Yes, they do. This is known from Cahana's work (13). The authors studied action potentials elicited in hippocampal slice cultures, studying the effect of both PRF and CRF at 42 OC. For CRF the source voltage must have been around $9 \mathrm{~V}$ but this caused a clear depression of the action potentials. At such a low voltage the elicited fields may seem inconsequential, unable to mediate the long lasting, stable improvement that characterizes the effect of PRF in successful cases. Indeed, a direct effect is unlikely, but an intermediate role is conceivable. Recently it has been reported that exposure of monocytes to PRF at a field strength of $500 \mathrm{~V} / \mathrm{m}$ and even lower causes expression of TNF $\alpha$ (15). This may of course be an unrelated event, but it could also be instrumental in a further trajectory. This trajectory is still unknown. There could be a local - or regional - effect on resident immune cells, or alternatively the afferent vagus nerve could be involved, activating the cholinergic anti-inflammatory tract (16). This would be concordant with experimental work suggesting the enhancement of noradrenergic and serotonergic descending pain inhibitory pathways following PRF treatment (17). The vagus nuclei have important connections to these tracts. Whatever happens, the immune system is a complex system, and it is known that such systems can make significant and stable changes by moving to a new attractor (18). A good example-but in the other direction-is the change in phenotype from active to regulatory of the invariant NKT lymphocytes following a stroke, causing the high mortality from pneumonia in these patients (19). This shows how drastic these changes may be. Much of what happens after PRF application is still in the clouds, but the contours are slowly getting clearer.

\section{Financial Disclosure}

There was no funding or donation involved in preparing this article. The authors have no financial interest in its content.

\section{References}

1. Sluijter ME, Teixeira A, Serra V, Balogh S, Schianchi P. Intra-articular application of pulsed radiofrequency for arthrogenic pain-report of six cases. Pain Pract. 2008;8(1):57-61.

2. Schianchi PM, Sluijter ME, Balogh SE. The Treatment of Joint Pain with Intra-articular Pulsed Radiofrequency. Anesth Pain. 2013; [Epub ahead of print] p.

3. Teixeira A, Sluijter ME. Intravenous application of pulsed radiofrequency- 4 case reports. Anesth Pain. 2013; [Epub ahead of print p.

4. Maier SF, Watkins LR. Cytokines for psychologists: implications of bidirectional immune-to-brain communication for understanding behavior, mood, and cognition. Psychol Rev. 1998;105(1):83-107.

5. McEwen BS. Stress, adaptation, and disease. Allostasis and allostatic load. Ann NYAcad Sci. 1998;840:33-44.

6. Higuchi Y, Nashold BS, Jr., Sluijter M, Cosman E, Pearlstein RD. Exposure of the dorsal root ganglion in rats to pulsed radiofrequency currents activates dorsal horn lamina I and II neurons. Neurosurgery. 2002;50(4):850-5.

7. Erdine S, Bilir A, Cosman ER, Cosman ER, Jr. Ultrastructural changes in axons following exposure to pulsed radiofrequency fields. Pain Pract. 2009;9(6):407-17.

8. Erdine S, Yucel A, Cimen A, Aydin S, Sav A, Bilir A. Effects of pulsed versus conventional radiofrequency current on rabbit dorsal root ganglion morphology. Eur J Pain.. 2005;9(3):251-6.

9. Imani F, Gharaei H, Rezvani M. Pulsed Radiofrequency of Lumbar Dorsal Root Ganglion for Chronic Postamputation Phantom Pain. Anesth Pain. 2012;1(3):194-7

10. Hai Liang Chua N, Halim W, Beems T, Vissers KCP. Pulsed Radiofrequency Treatment for Trigeminal Neuralgia. Anesth Pain. 2012;1(4):257-61.

11. Cosman ER, Jr., Cosman ER, Sr. Electric and thermal field ef fects in tissue around radiofrequency electrodes. Pain Med.. 2005;6(6):405-24.

12. Imani F. Using Pulsed Radiofrequency for Chronic Pain. Anesth Pain. 2012;1(3):155-6.

13. Cahana A, Vutskits L, Muller D. Acute differential modulation of synaptic transmission and cell survival during expo- 
sure to pulsed and continuous radiofrequency energy. J Pain. 2003;4(4):197-202.

14. Taverner MG, Ward TL, Loughnan TE. Transcutaneous pulsed radiofrequency treatment in patients with painful knee awaiting total knee joint replacement. Clin J Pain. 2010;26(5):429-32.

15. Van Duijn B. Exploration of anti-inflammatory effect of PRF at the cellular level. International Symposium "Invasive Procedures in Motion”; 2011; January 21-22; Nottwil, Switzerland.

16. Czura CJ, Tracey KJ. Autonomic neural regulation of immunity.J
Intern Med. 2005;257(2):156-66.

17. Hagiwara S, Iwasaka H, Takeshima N, Noguchi T. Mechanisms of analgesic action of pulsed radiofrequency on adjuvant-induced pain in the rat: roles of descending adrenergic and serotonergic systems. Eur J Pain. 2009;13(3):249-52.

18. Callard R, George AJ, Stark J. Cytokines, chaos, and complexity. Immunity. 1999;11(5):507-13.

19. Meisel C, Meisel A. Suppressing immunosuppression after stroke. N Engl J Med. 2011;365(22):2134-6. 